\title{
Daily synoptic conditions associated with large fire occurrence in Mediterranean France: evidence for a wind-driven fire regime
}

\author{
J Ruffault $^{1,2}$, V Moron ${ }^{2,4}$, R M Trigo ${ }^{3}$ and T Curt ${ }^{1}$ \\ ${ }^{1}$ IRSTEA, UR EMAX, Aix en Provence, France \\ ${ }^{2}$ Aix-Marseille University, CEREGE UM 34 CNRS, Aix en Provence, France \\ ${ }^{3}$ IDL, University of Lisbon, Lisbon, Portugal \\ ${ }^{4}$ IRI, Columbia University, Palisades, USA \\ E-mail: julien.ruff@gmail.com_
}

\begin{abstract}
Changes in wildfire activity in the Mediterranean area over recent decades increase the need for a better understanding of the fire-weather relationships and for the development of reliable models to improve fire danger prediction. This study analyses daily synoptic and local weather conditions associated with the occurrence of summer large fires (LF; >120 ha) in Mediterranean France during recent decades (1973-2013). The links between fire and synoptic conditions are analysed with composites of meteorological fields and a parsimonious synoptic weather type (WT) classification based on sea level pressure and winds at $925 \mathrm{hPa}$. A cluster analysis is used to identify 5 homogeneous regions with similar variations in seasonal fire activity. Our results reveal a dominant wind-driven fire regime, i.e wind conditions are the main factor explaining why fire become large, though substantial temporal and spatial variations are observed. Thus, most LFs occur under the “Atlantic Ridge” WT i.e. combining an anticyclonic ridge over eastern Atlantic and a cyclonic anomaly stretched from the North Sea to Central/Eastern Europe and Mediterranean basin. This pattern is significantly related at local scale to fast continental dry winds. By contrast, only a few LFs occur under WTs characterized by anomalously warm local-scale conditions ('Blocking' WTs), particularly under very warm and dry conditions such as during the outstanding 2003 summer. These "blocking" LFs occur preferentially in the western part of the region. These results offer promising developments for the improvement of fire danger predictions and operational management.
\end{abstract}

\section{Keywords}

Large fires; Mediterranean ecosystems; weather types; synoptic climatology; fire weather; southern France. 
Author-produced version of the article published in International Journal of Climatology, 2017, 37, 1, 524-533.

The original publication is available at https://rmets.onlinelibrary.wiley.com/doi/10.1002/joc.4680

DOI: $10.1002 /$ joc.4680

\section{Introduction}

Wildfire is a widespread process in the Mediterranean basin, burning 0.5 million hectares of forests and wooded areas per year on average (San-Miguel-Ayanz et al., 2009). Among the numerous human and biophysical influences on fires, climate and weather are key drivers of fire start and spread. But isolating the atmospheric processes that influence wildfire activity has complicated the ability to model wildfire and hamper the effectiveness of operational fire management. Climate and weather control fire activity through four main processes intervening at different time scales (Swetnam and Betancourt, 1990; Barbero et al., 2014) At decadal time scale, climate influence fuel composition and structure. At annual to seasonal time scales, antecedent atmospheric conditions (i.e. years or seasons prior to wildfire seasons) limit or promote the growth of fine fuels. Then, prior and during the fire season, daily to monthly atmospheric variability control the changes in fuel moisture content. Finally, short-term (hourly to daily) fluctuations in relative humidity, wind speed and temperature may influence fire ignition, intensity and propagation.

There is much debate about whether the dominant factors driving the interannual variability in fire activity are related to fuel amount or fuel moisture (e.g. Pausas and Paula, 2012; Koutsias et al., 2013). But once fuel conditions are appropriate to sustain burning, instantaneous weather conditions then largely explain the behaviour and rate of spread of the typical woody-fuelled crown fires observed in Mediterranean ecosystems (Pyne et al., 1996). These daily weather conditions not only influence large fire (LF) occurrence (Pereira et al., 2005; Kassomenos, 2010; Ruffault and Mouillot, 2015) but are aslo related to exceptional fire seasons, such as in Portugal in 2003 (Trigo et al., 2006) or in Greece in 2007 (Amraoui et al., 2013).

Some recent studies across the Euro-Mediterranean countries emphasized that LF preferentially occur under synoptic patterns associated with high temperature days (e.g. Pereira et al., 2005; Trigo et al., 2013; Hernandez et al., 2015a,b). But these relationships have not been investigated specifically for the fire-prone region of Mediterranean France. Yet, its unique geographic, topographic and fire-suppression historical situation within the Euro-Mediterranean area represent a substantial number of distinct factors known to affect fire climatology (e.g. Parks et al., 2012; Ruffault and Mouillot, 2015). In addition, this area is characterized by a large variety of climatic conditions, vegetation, and anthropogenic pressures (Fréjaville and Curt, 2015), and therefore provides an interesting case study for fire meteorology.

Linking large-scale synoptic patterns with regional to local-scale fire data and fire-weather conditions is an effective way to construct a fire-weather climatology (e.g. Levin and Saaroni, 1999; Skinner et al., 2002; Pereira et al., 2005; Crimmins, 2006; Wastl et al., 2013; Laboisier et al., 2014). First, these atmospheric patterns offer a sound physical basis for the development of more relevant fire risk indices. Secondly, synoptic variables (usually sea level pressure, geopotential height at 500 $h P a$ or tropospheric winds), are often better simulated by global and regional circulation models than local-scale surface climatic variables such as temperature and precipitation (Conway and Jones, 1998; Trigo and Palutikof, 2001). Classifications based on synoptic patterns are therefore particularly suitable for either short-term fire risk forecasts or long-term fire regime projections.

The objective of this study is to relate the occurrence of large fires (LF) in south-eastern France to their respective daily weather conditions and synoptic circulation patterns during recent decades (1973-2013) by using composites analyses and an automated classification of synoptic patterns (weather types, WT). Through this objective we aim here to (i) assess the fire weather-relationship in southeastern France and its temporal and spatial variations, to (ii) evaluate the capacity of a parsimonious weather type classification to capture the conditions associated to LFs. 
Author-produced version of the article published in International Journal of Climatology, 2017, 37, 1, 524-533.

The original publication is available at https://rmets.onlinelibrary.wiley.com/doi/10.1002/joc.4680

DOI: $10.1002 /$ joc.4680

\section{Datasets}

Three datasets were used:

(i) The location, date and final size of forest fires were extracted for the period 1973-2013 from the PROMETHEE fire database (www.promethee.fr). This database is managed by French forest services for the 15 French administrative districts located in Southeastern France and covers a total area of $80,500 \mathrm{~km}^{2}$ (Figure 1a). The database provides for each fire, the associated burned area, day of ignition and ignition location on a $2 \mathrm{~km} \times 2 \mathrm{~km}$ national reference grid. Fire duration in the study area is short and fires are contained within one day of ignition. Each fire burning at least $120 \mathrm{ha}$ (i.e. corresponding to the $95^{\text {th }}$ percentiles of all fires in the database) was then classified as Large Fire.

(ii) Daily atmospheric data were extracted from the NCEP/NCAR reanalysis data (Kalnay et al., 1996; $2.5 \times 2.5^{\circ}$ spatial resolution) for the same period as the fire database (1973-2013) for North Atlantic and Europe: $60^{\circ} \mathrm{W}-40^{\circ} \mathrm{E}, 25^{\circ} \mathrm{N}-70^{\circ} \mathrm{N}$. To obtain a simple but comprehensive characterization of the atmospheric circulation, sea level pressure (SLP), zonal and meridional winds at $925 \mathrm{hPa}$ (W_925) were selected. The $925 \mathrm{hPa}$ level was chosen because it is representative of the low troposphere state without suffering from some problems affecting nearsurface reanalysis variables (Trigo et al., 2004).

(iii) Daily historical observations of weather variables were obtained from the SAFRAN dataset (Vidal, 2010) for the same period as the fire database (1973-2013). SAFRAN is a reanalysis of surface observations on an $8 \mathrm{~km}$ resolution grid over France. Three variables (wind speed, relative humidity, and temperature) known to play a key role in the spreading of wildfires (Pyne et al., 1996) were extracted.

\section{Fire regime and atmospheric patterns in south-eastern France}

\subsection{Spatial and temporal variability of fire activity}

In south-eastern France, most of the LFs occur within the coastal Mediterranean areas whereas the mountains (Pyrenees, Southern Massif Central and Southern Alps) are less affected (Figure 1b; see also Fréjaville and Curt, 2015). As in other Mediterranean countries, the summertime plant water deficit related to dry and hot conditions (Ruffault et al., 2013) leads to a clear annual peak of LFs during this season (Figure 2a). The average yearly burnt area during summer season (July and August, -JA-) is $139 \mathrm{~km}^{2}$.year ${ }^{-1}$, $66 \%$ of annual burnt area in southeastern France. The JA frequency of LFs is highly correlated to JA burnt area (Spearman correlation, $r h o=0.89, p<0.01$ ), but also to yearly burnt area $(r h o=0.84, p<0.01)$. As a result of climate variability (Ruffault et al., 2013), the yearly and JA frequencies of LFs are highly variable (Figure $2 \mathrm{~b}$ ). The drop in fire activity around 1990 is due to the introduction of a new fire policy at the national level (Ruffault and Mouillot, 2015).

\section{$\underline{3.2}$ Fire regime zonation}

In this section, we aim to identify contiguous subregions characterized by similar inter-annual variability in LF occurrences to test for spatial dissimilarities in the response of fire activity to synoptic patterns. Fire zonation was performed using standard $k$-means method applied to the summer normalized burnt area (NBA) on each $2 \mathrm{~km}^{2}$ reference gridcell. NBA was defined as the ratio of the annual summer BA to the total summer BA over the studied period (1973-2013). To reduce the effect of small-scale fragmentation of landscapes, an inverse distance weighting function 
Author-produced version of the article published in International Journal of Climatology, 2017, 37, 1, 524-533.

The original publication is available at https://rmets.onlinelibrary.wiley.com/doi/10.1002/joc.4680

DOI: $10.1002 /$ joc.4680

was previously applied to NBA. Preliminary results show that a $30 \mathrm{~km}$ moving window was the smallest value to obtain a contiguous fire zonation (not shown). The final number of clusters was then determined heuristically as a trade-off between the understanding of fine scale drivers of LF occurrence and a sufficient sample size for statistical analyses.

Five clusters (Figure 1b) identified contiguous grid cells on a longitudinal gradient (hereafter R1 to R5, numbered west to east). It should be noted that Corsica (R5), whose specific geographical features and human practices are fairly different from the other four continental regions (Mouillot et al., 2003) is identified as an independent cluster. Fire activity is different between these subregions (see Figure S1). R5 is by far the most fire-prone region with a total of 281 summer LFs during the considered period, which accounts for $41.5 \%$ of total number of LFs. R1, R2, R3 and R4 respectively account for $10 \%(n=64), 15 \%(n=105), 19 \%(n=129)$ and $14 \%(n=98)$ of the total number of LFs.

\subsection{The role of synoptic patterns in large fire occurrence}

Composites of anomaly fields of sea level pressures (SLP) and winds at $925 \mathrm{hPa}$ (Z_925) were computed as the difference between the mean values for the LF days to the JA 1973-2013 average. These anomalies were considered here both at regional (over the whole study area) and subregional (over each cluster identified in section 3.2) scales.

The anomalies associated to LF occurrences over the whole study area emphasize the primary role of regional-scale winds in fire activity. Indeed, most of the LFs are associated with an anticyclonic ridge over the eastern Atlantic and Western Europe combined with a cyclonic anomaly from Scandinavia to Central Europe (Figure 3a). Combined with local topography, this atmospheric configuration tends to increase the N-NW component of low-level winds, namely "Tramontane" (in Languedoc-Roussillon) and "Mistral" (in lower Rhône Valley and Provence). A similar atmospheric pattern is associated to LFs at subregional scale (R1 to R5 maps on Figure 3), but one of the barometric centres identified above could be strengthened/weakened and/or slightly shifted. For example, the zonal barometric gradient between Western and Central Europe, which increases wind speed in case of northerly winds, is especially reinforced for R3 (located downstream of the Rhone Valley). On the contrary, the anticyclonic pole is weakened for R4, which is, at least partly, shadowed from "Mistral”.

\section{Weather type classification}

Daily synoptic-scale atmospheric patterns were classified using a standard $k$-means algorithm (Michelangeli et al., 1995). JA daily values of sea level pressure (SLP) and zonal and meridional wind components at $925 \mathrm{hPa}$ were previously normalized at each grid point and subjected to an empirical orthogonal function analysis with the 27 leading PCs accounting for $75 \%$ of the total variance. According to the classifiability criteria (Michelangeli et al., 1995), the optimal partition is obtained for 4 WTs (as shown in Figure S2). This 4-clusters solution fits quite well with the one found by Cassou et al. (2005; hereafter CTP05) over a similar area but for a different input variable and time period (June-August 1951-2003). The four WTs show distinctive atmospheric anomalies but a similar climatological frequency (Figure 4). Interannual frequency of these WTs is highly variable without any significant temporal trends (Man-Kendall test; $p>0.1$; Figure S3).

The first WT (Figure 4a) is characterized by deep negative SLP anomalies over the eastern North Atlantic and weaker positive SLP anomalies over Scandinavia and central Europe, and is fairly similar to "Atlantic Low - Atl.Low - " pattern of CTP05. This pattern is related to warm anomalies in southeastern France, ranging from $+0.5^{\circ} \mathrm{C}$ on the coast to $+2.5^{\circ} \mathrm{C}$ in the mountainous north part 
Author-produced version of the article published in International Journal of Climatology, 2017, 37, 1, 524-533.

The original publication is available at https://rmets.onlinelibrary.wiley.com/doi/10.1002/joc.4680

DOI: $10.1002 /$ joc.4680

(Figure 5). This WT is also associated with negative wind anomalies all over the study area, weak positive RH anomalies close to the Mediterranean Sea and negative RH anomalies in the Northern part of the region (Fig. 5).

The second WT (Figure 4b) is characterized by a positive SLP anomaly on Northern North Atlantic and two main centers of negative SLP anomaly, over Scandinavia and in the central North Atlantic. Such pattern tends to reduce or block the progression of westerlies across the North Atlantic and is highly similar to negative NAO phase, $-N A O--$ in CTP05. This WT is associated with cold and dry anomalies in southeastern France while winds tend to be slightly stronger than usual in the central part (Figure 5)

The third WT (Figure 4c) is dominated by vast positive SLP anomalies covering almost the whole Europe and peaking around the British islands. This configuration is associated with a strengthening and a regional-scale E-NE shift of the Azores anticyclone, promoting usually warm, dry air and sunny conditions across the whole Europe. It is consistent with Blocking WT of CTP05 and is associated with weak warm and dry anomalies on the western part of our region. Wind speeds are reduced in the southeastern part and Corsica, but slightly enhanced over the western part (Figure 5). The last WT (Figure 4d) displays a strong anticyclonic anomaly over the eastern Atlantic associated to a cyclonic anomaly centred in the North Sea stretched toward the Mediterranean Sea. This WT matches perfectly the «Atlantic Ridge - Atl.Ridge-» of CTP05 and produces cold anomalies and faster continental wind than usual over southeastern France (Figure 5). Temperature anomalies range from $-0.5^{\circ} \mathrm{C}$ in the SE to $-2.5^{\circ} \mathrm{C}$ in the western part of the region (Figure 5) This WT produces also, on average, the fastest winds, mostly downstream of the Rhone Valley and in Languedoc-Roussillon (Figure 5). Particularly important within the context of this work, Atl.Ridge matches rather well with the SLP and Z_925 composites associated with LFs, especially those occurring in R1-R3 (igure 3).

\section{Links between fire occurrence and weather types}

In this section, we intend to identify the critical fire WTs. To do that, we defined the WT efficiency coefficient (eff) as the ratio of the observed number of fires for each WT to the expected number of LFs for this same WT. The expected number of fires is the number of fires observed in each region multiplied by the WT frequency, i.e. the number of fires expected by chance alone. A WT efficiency higher (lower) than 1 therefore indicates that fires preferentially (do not) occur under this synoptic pattern. In addition and to to assess whether atmospheric conditions associated to LF are different from those associated to all fires, this procedure was performed separately for all fires ignitions and for LFs.

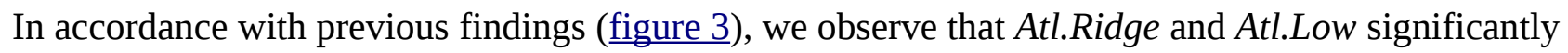
increase $(e f f=1.44, p<0.01)$ and decrease $(e f f=0.54, p<0.01)$ the probability of LF occurrence, respectively (Table 1). These results emphasize the primary role of wind speed in the occurrence of LFs, which is on average more relevant than temperature and relative humidity. By contrast, NAOincreases the occurrence of all fires $(e f f=1.07, p<0.01)$, which highlights the major role of dry air conditions in fire ignition probability. In addition, the stronger WT efficiency associated to LFs reflects the higher importance of daily weather conditions in the probability LF occurrence compared to all fires ignitions. 
However,WT efficiency is unequal at subregional scale. In the three most fire-prone subregions located downstream of the lower Rhône Valley (R3-R5), WT efficiency follows the regional pattern, and Atl.Ridge and Atl.Low significantly increase and decrease probability of LF occurrence, respectively. By contrast, in the central part of the region (R2), LF occurrence is higher than expected for Blocking (eff $=1.48, p<0.01$ ), which is accordingly associated with weak anomalously warmer, drier and windier air conditions on the western part of our region (Figure 5 , third column). However, the number of LF is lower than expected for Atl.Ridge $(e f f=0.68, p<0.05)$ in this region. In the most western part (R1), most fires are related to $N A O-(e f f=1.71, p<0.01)$, which is related to anomalously drier and windier air conditions in this region (Figure 5, second column). We also observe an important temporal heterogeneity in WT efficiency (as shown in Figure S4); for instance, Atl.Low and NAO- account for a large amount of LF during a few fire-prone years, such as during the hot summer of 2003.

To clarify the impact of regional temperature and wind anomalies on fire activity, we report for each WT these anomalies during standard conditions (black dots), during LF days (green dots) and during LF days of summer of 2003 (blue dots) (figure 6). Overall, temperature and wind anomalies during LF days are broadly similar to those observed during all days, although the former are usually windier (particularly for Atl.Ridge) and warmer (particularly for Atl.Low). By contrast, LF events in 2003 (blue dots) largely differ: during this summer, LF occurrences are systematically associated with warm but low wind speeds anomalies. 
Author-produced version of the article published in International Journal of Climatology, 2017, 37, 1, 524-533.

The original publication is available at https://rmets.onlinelibrary.wiley.com/doi/10.1002/joc.4680

DOI: $10.1002 /$ joc.4680

\section{Discussion}

This study provides further evidence that daily weather conditions greatly influence the occurrence of summer LFs in the Mediterranean area (e.g. Trigo et al., 2006; Amraoui et al., 2013). These local weather conditions are related to regional synoptic patterns (e.g. Pereira et al., 2005). In Mediterranean France, LF occurrence is primarily driven by a wind-forced mode, i.e. by synoptic conditions that tend to increase dry surface winds over the region. This atmospheric pattern characterized by an anticyclonic ridge over the Western Europe and near North Atlantic associated with a cyclonic anomaly stretched from Scandinavia to Central Europe and Mediterranean basin (Figure 3). The exact location (longitude) of the anticyclone/low pressure pair is critical to determine the area affected by increasing continental winds and/or anomalous warm and dry air conditions (Figures 4 and 5). Two weather types (WT), NAO- and particularly Atl.Ridge, characterized by cool temperature, fast wind and low relative humidity, are related with more LF than usual (i.e. LFs are one and a half times more likely to occur during Atl.Ridge). By contrast, the two others WTs (Blocking and particularly Atl.Low), characterized by warm anomalies, wet air and moderate wind conditions, are related to fewer LFs than usual (i.e. LFs are one and a half times less likely to occur during Atl.Low).

This fire-weather relationship is different from the one observed in most of the other EuroMediterranean countries, where LFs have been generally associated to "blocking" synoptic conditions, which promote warm surface conditions. This is the case in particular in the Iberian Peninsula (Pereira et al., 2005; Rassilla et al., 2010; Trigo et al., 2013; Cardil et al., 2014a), in Italy (Cardil et al., 2014b) and in eastern Mediterranean (Levin and Saaroni, 1999; Kassomenos, 2010; Papadopoulos et al., 2013). From a climatic point of view, this peculiar pattern can be explained by the out-of-phase relationship observed in southeastern France between daily averaged wind speed and temperature anomalies (Spearman correlation, $r h o=-0.46, p<0.001$ ). Strong winds usually blow from the north and are generally associated with cold anomalies. By contrast, heat waves are generally associated with calm conditions or weak southerly winds (Figure 5). Thus unlike Iberia, Italy or the Balkans, southeastern France generally experience warm conditions in combination with southward advection conveying moisture from the Mediterranean Sea, which could reduce the probability of LF occurrence. Nevertheless, although synoptic patterns provide a consistent explanation for this differential fire-weather relationship, non-climatic factors that might differ among countries (relative to natural and historical causes) should also be considered. Fire suppression practices (Ruffault and Mouillot, 2015), ignition patterns (Parks et al., 2012) or fuel structure and land use (Littell et al., 2009; Higuera et al., 2015) are all factors that might also impact the fire-weather relationships. Besides, the wind-driven regime observed here is in accordance with the conditions identified as major drivers of fire spread in temperate and Mediterranean areas where fires are actively suppressed, because of the inefficiency of suppression during windy days (e.g. Podur and Wotton, 2011; Ruffault and Mouillot, 2015).

While we observed that fire activity is mainly controlled by positive wind anomalies (favoured during Atl.Ridge episodes), 17\% of LF still occurs under warm anomalies (favoured during Atl.Low episodes). Interestingly, most of these "Atl.Low fires" were observed during the summer of 2003, when southern France experienced particularly hot (e.g. Trigo et al., 2005) and dry (Reichstein et al., 2007) conditions. LF can therefore be divided into two main categories: those (most of them in current climate) driven by strong mistral and/or tramontane winds associated with instantaneous anomalously dry air conditions (i.e. wind-forced mode of Hernandez et al., 2015a,b) and the others occurring with comparatively weak winds but hotter weather (i.e. heat-wave mode of Hernandez et al., 2015a,b). Interestingly, we also observe some regional dissimilarity in the fire-weather 
Author-produced version of the article published in International Journal of Climatology, 2017, 37, 1, 524-533.

The original publication is available at https://rmets.onlinelibrary.wiley.com/doi/10.1002/joc.4680

DOI: $10.1002 /$ joc.4680

relationship: the eastern part of the region (R3, R4 and R5 clusters defined in Figure 3) follows the wind-forced mode observed at regional scale where as LFs occurs preferentially under NAO- and Blocking episodes in the western part (R1 and R2). Such pattern is quite similar to the one observed in Mediterranean ecosystems of California, where most of LF occur during Santa Ana winds episodes but where fire also spread during hot days if conditions are exceptionally dry (e.g. Jin et al., 2014). This dichotomous typology also matches the one that was proposed by Duane et al. (2015), who distinguish fires depending on the dominant factor affecting spread, i.e. meteorology (wind-driven fires) or fuel (convective fires).

The parsimonious WT classification of synoptic patterns is relevant for assessing the fire-weather relationship in Mediterranean France. When coupled with a fire zonation, this approach also explains the asynchronous fire activity observed between subregions (R1-R5; Figure S2, Table 1). Given its parsimonious, informative and easily reproducible nature, this methodology is a promising tool for fire danger forecasting in Mediterranean France and could be extended in areas with similar fire-regime characteristics, i.e. where instantaneous weather conditions control LF occurrence and where fire duration generally does not exceed one day. But two key points should be emphasized here. First, LFs were defined as fires whose size is above a threshold of $120 \mathrm{ha}$. This fire size threshold is rather important in the Euro-Mediterranean context (Ricotta et al., 2001) but should be adapted according to the studied area and period considered. Nevertheless, it should be noted here that changing this fire size (from 30 to $250 \mathrm{ha}$ ) does not impact the nature of the fire-weather relationship in southeastern France but rather alter the strength of this relationship (i.e. its WT efficiency, not shown). Second, whether there is enough fuel and whether the fuel is dry enough to sustain fire are two other weather-related factors affecting fire occurrence and its behaviour. Especially important for estimating the length and intensity of the fire season, these two factors should be integrated for a more thorough fire-climatology analysis, which would be readily usable for projecting fire danger (see for instance Sousa et al., 2015). In a region where projected changes for the next decades are well aligned confirming in a general warming and vegetation drying (Ruffault et al., 2014; Mariotti et al., 2015), the development of fire danger model based on a few synoptic patterns would greatly benefit long-term fire management and short-term fire resource allocations. 
Author-produced version of the article published in International Journal of Climatology, 2017, 37, 1, 524-533.

The original publication is available at https://rmets.onlinelibrary.wiley.com/doi/10.1002/joc.4680

DOI: $10.1002 /$ joc.4680

\section{Acknowledgements}

This work is a contribution to the Labex OT-Med (ANR-11-LABEX-0061) funded by the "Investissements d'Avenir", French Government program of the French National Research Agency (ANR) through the A*Midex project (ANR-11-IDEX-0001-02). 
Author-produced version of the article published in International Journal of Climatology, 2017, 37, 1, 524-533.

The original publication is available at https://rmets.onlinelibrary.wiley.com/doi/10.1002/joc.4680

DOI: $10.1002 /$ joc.4680

\section{References}

Amraoui M, Liberato MLR, Calado TJ, DaCamara CC, Coelho LP, Trigo RM, Gouveia CM. 2013. Fire activity over Mediterranean Europe based on information from Meteosat-8. Forest Ecology and Management 294: 62-75.

Barbero R, Abatzoglou JT, Kolden CA, Hegewisch KC, Larkin NK and Podschwit H. 2014. Multiscalar influence of weather and climate on very large-fires in the Eastern United States.

International Journal of Climatology.

Cardil A, Eastaugh CS, Molina DM. 2014a. Extreme temperature conditions and wildland fires in Spain. Theorethical and Applied Climatology 118.

Cardil A, Salis M, Spano D, Delogu G, Molina Terrén D. 2014b. Large wildland fires and extreme temperatures in Sardinia (Italy). iForest - Biogeosciences and Forestry 7: 161-168.

Cassou C, Terray L, Phillips AS. 2005. Tropical Atlantic influence on European heat waves. Journal of Climate 18: 2805-2811.

Conway D, Jones PD. 1998. The use of weather types and air flow indices for GCM downscaling. Journal of Hydrology 212-213: 348-361.

Crimmins MA. 2006. Synoptic climatology of extreme fire-weather conditions across the southwest United States. International Journal of Climatology 26: 1001-1016.

Duane A, Piqué M, Castellnou M, Brotons L. 2015. Predictive modelling of fire occurrences from different fire spread patterns in Mediterranean landscapes. International Journal of Wildland Fire 24: 407-418.

Fréjaville T, Curt T. 2015. Spatiotemporal patterns of changes in fire regime and climate: defining the pyroclimates of south-eastern France (Mediterranean Basin). Climatic Change 129: 239-251. Hernandez C, Drobinski P, Turquety S. 2015a. How much does weather control fire size and intensity in the Mediterranean region? Annales Geophysicae 33: 931-939.

Hernandez C, Drobinski P, Turquety S, and Dupuy JL. 2015b. Size of wildfires in the EuroMediterranean region: observations and theoretical analysis. Natural Hazards and Earth System Science 15: 1331-1341.

Higuera PE, Abatzoglou JT, Littell JS, Morgan P. 2015. The Changing Strength and Nature of FireClimate Relationships in the Northern Rocky Mountains, U.S.A., 1902-2008. Plos One 10, e0127563.

Jin Y, Randerson JT, Faivre N, Capps S, Hall A, Goulden ML. 2014. Contrasting controls on wildland fires in Southern California during periods with and without Santa Ana winds. Journal of Geophysical Research: Biogeosciences 119: 432-450.

Kalnay E, Kanamitsu M, Kistler R, Collins W, Deaven D, Gandin L, Iredell M, Saha S, White G, Woollen J and others. 1996. The NCEP/NCAR 40-year reanalysis project. Bulletin of the American meteorological Society 77: 437-471.

Kassomenos P. 2010. Synoptic circulation control on wild fire occurrence. Physics and Chemistry of the Earth 35: 544-552.

Koutsias N, Xanthopoulos G, Founda D, Xystrakis F, Nioti F, Pleniou M, Mallinis G, Arianoutsou M. 2013. On the relationships between forest fires and weather conditions in Greece from long-term national observations (1894-2010). International Journal of Wildland Fire 22: 493-507.

Labosier CF, Frauenfeld OW, Quiring SM, Lafon CW. 2014. Weather type classification of wildfire ignitions in the central Gulf Coast, United States. International Journal of Climatology.

Levin N, Saaroni H. 1999. Fire weather in Israel—synoptic climatological analysis. GeoJournal 47: $523-538$. 
Author-produced version of the article published in International Journal of Climatology, 2017, 37, 1, 524-533.

The original publication is available at https://rmets.onlinelibrary.wiley.com/doi/10.1002/joc.4680

DOI: $10.1002 /$ joc.4680

Littell JS, Mckenzie D, Peterson DL, Westerling AL. 2009. Climate and wildfire area burned in western U.S. ecoprovinces, 1916-2003. Ecological Applications 19: 1003-1021.

Mariotti A, Pan Y, Zeng N, Alessandri A. 2015. Long-term climate change in the Mediterranean region in the midst of decadal variability. Climate Dynamics 44: 1437-1456.

Michelangeli PA, Vautard R, Legras B. 1995. Weather regimes: Recurrence and quasi stationarity. Journal of the Atmospheric Sciences 52: 1237-1256.

Mouillot F, Ratte JP, Joffre R, Moreno JM, Rambal S. 2003. Some determinants of the spatio-temporal fire cycle in a mediterranean landscape (Corsica, France). Landscape Ecology 18: 665-674.

Papadopoulos A, Paschalidou AK, Kassomenos PA McGregor G. 2013. Investigating the relationship of meteorological/climatological conditions and wildfires in Greece. Theoretical and Applied Climatology 112, 113-126.

Parks S, Parisien M, Miller C. 2012. Spatial bottom-up controls on fire likelihood vary across western North America. Ecosphere 3: 1-20.

Pausas JG, Paula S. 2012. Fuel shapes the fire-climate relationship: evidence from Mediterranean ecosystems. Global Ecology and Biogeography 21: 1074-1082.

Pereira MG, Trigo RM, da Camara CC, Pereira J, Leite SM. 2005. Synoptic patterns associated with large summer forest fires in Portugal. Agricultural and Forest Meteorology 129: 11-25. Plaut G, Simonnet E. 2001. Large-scale circulation classification, weather regimes, and local climate over France, the Alps and Western Europe. Climate Research 17: 303-324.

Podur J, Wotton BM. 2011. Defining fire spread event days for fire-growth modelling. International Journal of Wildland Fire 20: 497.

Pyne SJ, Andrews PL, Laven RD. 1996. Introduction to wildland fire. John Wiley \&amp; Sons Inc. Rasilla DF, García-Codron JC, Carracedo V, Diego C. 2010. Circulation patterns, wildfire risk and wildfire occurrence at continental Spain. Physics and Chemistry of the Earth 35: 553-560.

Reichstein M, Ciais P, Papale D, Valentini R, Running S, Viovy N, Cramer W, Granier A, Ogée J, Allard V, Aubinet M, Bernhofer C, Buchmann N, Carrara a., Grünwald T, Heimann M, Heinesch B, Knohl a., Kutsch W, Loustau D, Manca G, Matteucci G, Miglietta F, Ourcival JM, Pilegaard K, Pumpanen J, Rambal S, Schaphoff S, Seufert G, Soussana JF, Sanz MJ, Vesala T and Zhao M. 2007. Reduction of ecosystem productivity and respiration during the European summer 2003 climate anomaly: a joint flux tower, remote sensing and modelling analysis. Global Change Biology 13: 634-651.

Ricotta C, Arianoutsou M, Diaz-Delgado R, Duguy B, Lloret F, Maroudi E, Mazzoleni S, Moreno J M, Rambal S, Vallejo R and Vázquez A. 2001. Self-organized criticality of wildfires ecologically revisited. Ecological Modelling 141: 307-311.

Ruffault J, Martin-StPaul NK, Duffet C, Goge F, Mouillot F. 2014. Projecting future drought in Mediterranean forests: bias correction of climate models matters! Theoretical and applied climatology 117: 113-122.

Ruffault J, Martin-StPaul NK, Rambal S, Mouillot F. 2013. Differential regional responses in drought length, intensity and timing to recent climate changes in a Mediterranean forested ecosystem. Climatic Change 117: 103-117.

Ruffault J, Mouillot F. 2015. How a new fire-suppression policy can abruptly reshape the fireweather relationship. Ecosphere, in press.

San-Miguel-Ayanz J, Pereira JMC, Boca R, Strobl P, Kucera J, Pekkarinen A. 2009. Forest fires in the european mediterranean region: Mapping and analysis of burned areas. Earth Observation of Wildland Fires in Mediterranean Ecosystems.189-203. 
Skinner WR, Flannigan MD, Stocks BJ, Martell DL, Wotton BM, Todd JB, Mason JA, Logan KA, Bosch EM. 2002. A $500 \mathrm{hPa}$ synoptic wildland fire climatology for large Canadian forest fires, 1959-1996. Theoretical and Applied Climatology 71: 157-169.

Sousa PM, Trigo RM, Pereira MG, Bedia J, Gutiérrez JM. 2015. Different approaches to model future burnt area in the Iberian Peninsula. Agricultural and Forest Meteorology 202: 11-25.

Trigo RM, García-Herrera R, Díaz J, Trigo IF, Valente MA. 2005. How exceptional was the early August 2003 heatwave in France? Geophysical Research Letters 32: 1-4.

Swetnam T, Betancourt J. 1990. Fire-Southern Oscillation Relations in the Southwestern United States. Science 249: 1017-120

Trigo RM, Pereira J, Pereira MG, Mota B, Calado TJ, Dacamara CC, Santo FE. 2006. Atmospheric conditions associated with the exceptional fire season of 2003 in Portugal. International Journal of Climatology 26: 1741-1757.

Trigo RM, Sousa PM, Pereira MG, Rasilla D, Gouveia CM. 2013. Modelling wildfire activity in Iberia with different atmospheric circulation weather types. International Journal of Climatology. Trigo RM, Trigo IM, DaCamara CC, Osborn TJ. 2004. Winter blocking episodes in the EuropeanAtlantic sector: Climate impacts and associated physical mechanisms in the reanalysis. Climate Dynamics 23: 17-28.

Vidal JP, Martin E, Franchistéguy L, Baillon M, Soubeyroux JM. 2010. A 50 year high resolution atmospheric reanalysis over France with the Safran system. International Journal of Climatology 30: $1627-1644$.

Wastl C, Schunk C, Lüpke M, Cocca G, Conedera M, Valese E, Menzel A. 2013. Agricultural and Forest Meteorology Large-scale weather types, forest fire danger, and wildfire occurrence in the Alps. Agricultural and Forest Meteorology 168: 15-25. 
Author-produced version of the article published in International Journal of Climatology, 2017, 37, 1, 524-533.

The original publication is available at https://rmets.onlinelibrary.wiley.com/doi/10.1002/joc.4680

DOI: $10.1002 /$ joc.4680

\section{Figures}
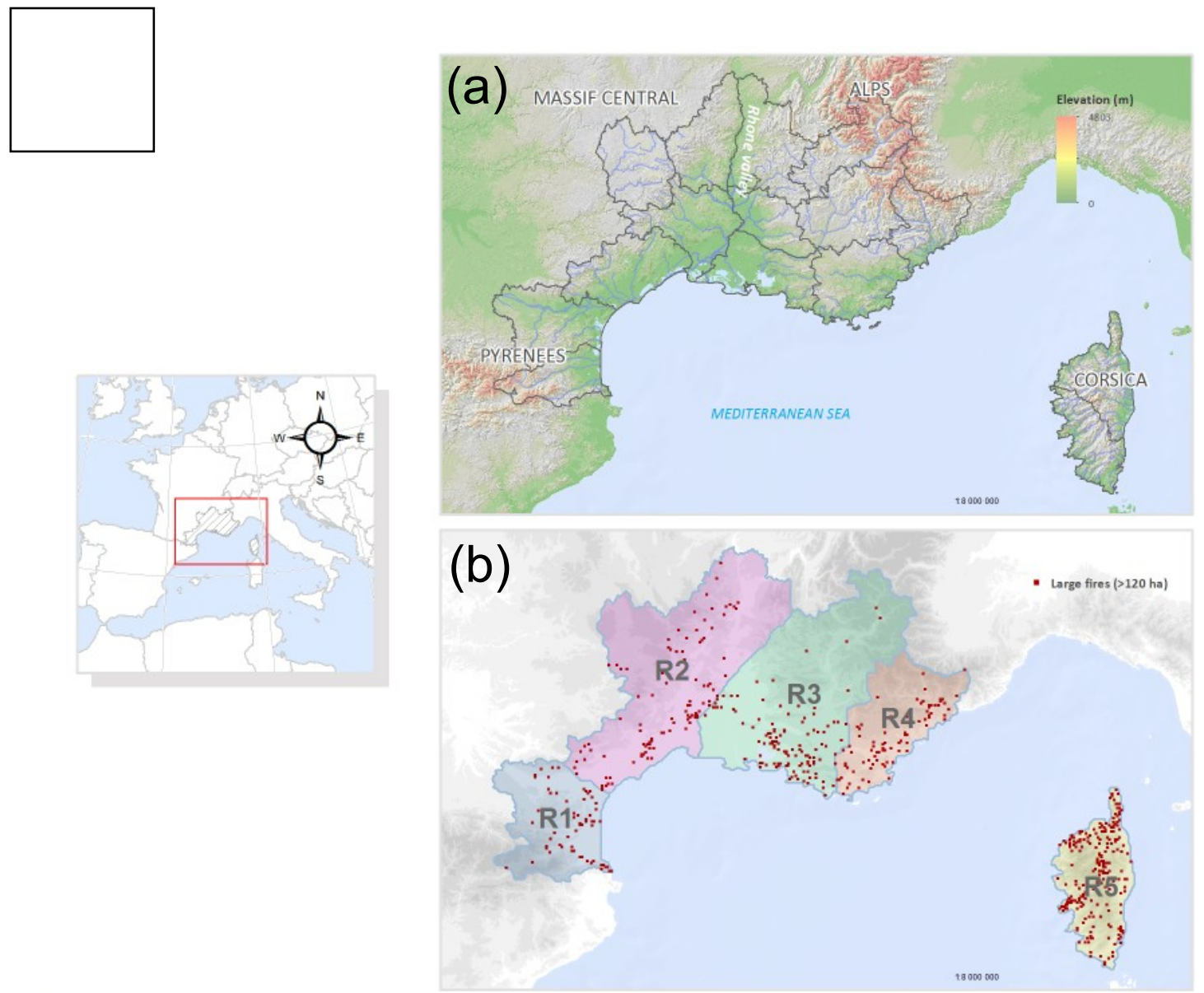

Figure 1: The domain of the analysis in southeastern France including a) the administrative borders and the main topographical features and $\mathbf{b}$ ) fire zonation and geographical location of large fires (>120 ha) for the period from 1973 to 2013.
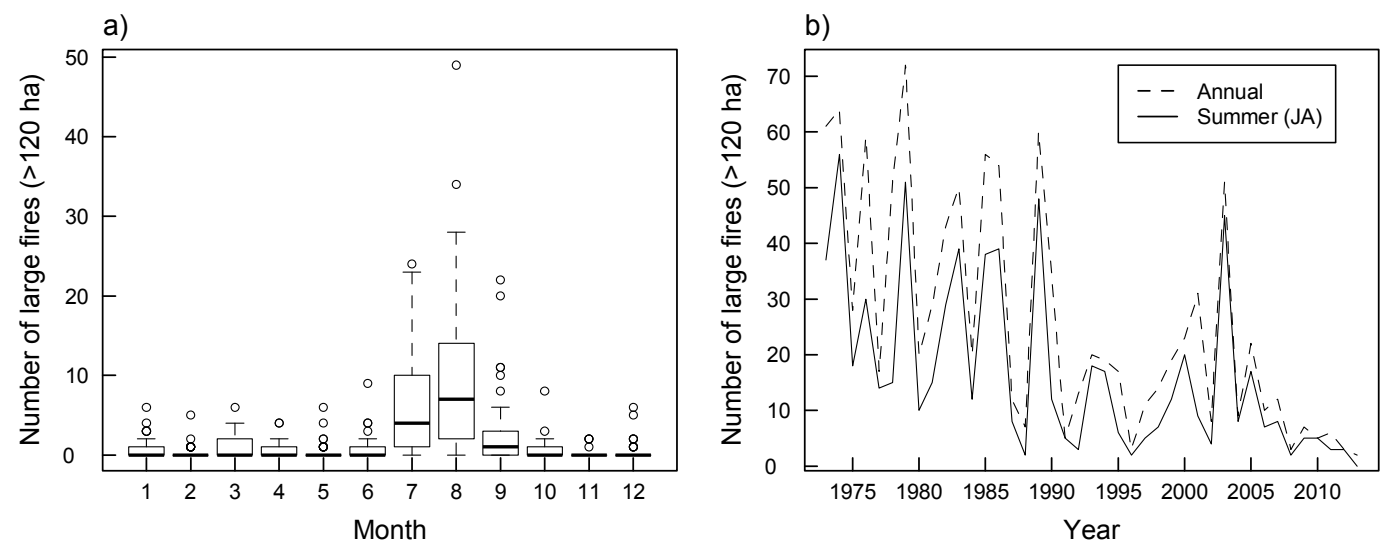
Author-produced version of the article published in International Journal of Climatology, 2017, 37, 1, 524-533.

The original publication is available at https://rmets.onlinelibrary.wiley.com/doi/10.1002/joc.4680

DOI: $10.1002 /$ joc.4680

Figure 2: statistics on large fires (> $120 \mathrm{ha}$ ) in southeastern France for the period 1973-2013. a) Box plots showing the annual cycle of the variability of monthly number of large fires (> $120 \mathrm{ha}$ ) and b) the yearly annual and summer (July and August) number of large fires

Author-produced version of the article published in International Journal of Climatology, 2017, 37, 1, 524-533.

The original publication is available at https://rmets.onlinelibrary.wiley.com/doi/10.1002/joc.4680

DOI: $10.1002 /$ joc.4680

Figure 3: Composite anomalies of sea level pressure (SLP; font color), zonal and meridional winds at $925 \mathrm{hPa}$ (Z_925; arrows) associated with the occurrence of large fires (LF; >120 ha) and represented here for each subregion for the period 1973-2013. Anomalies were computed as the difference between the mean values for the days when at least one LF occurs to the summer (July and August) 1973-2013 average. SLP anomalies are represented only in areas where the anomaly is statistically significant at the $1 \%$ level (or $99 \%$ confidence level) computed with a two-tailed t-test. Z_925 anomaly was represented if one of the two anomalies (meridional or zonal) was significant at the $1 \%$ level.
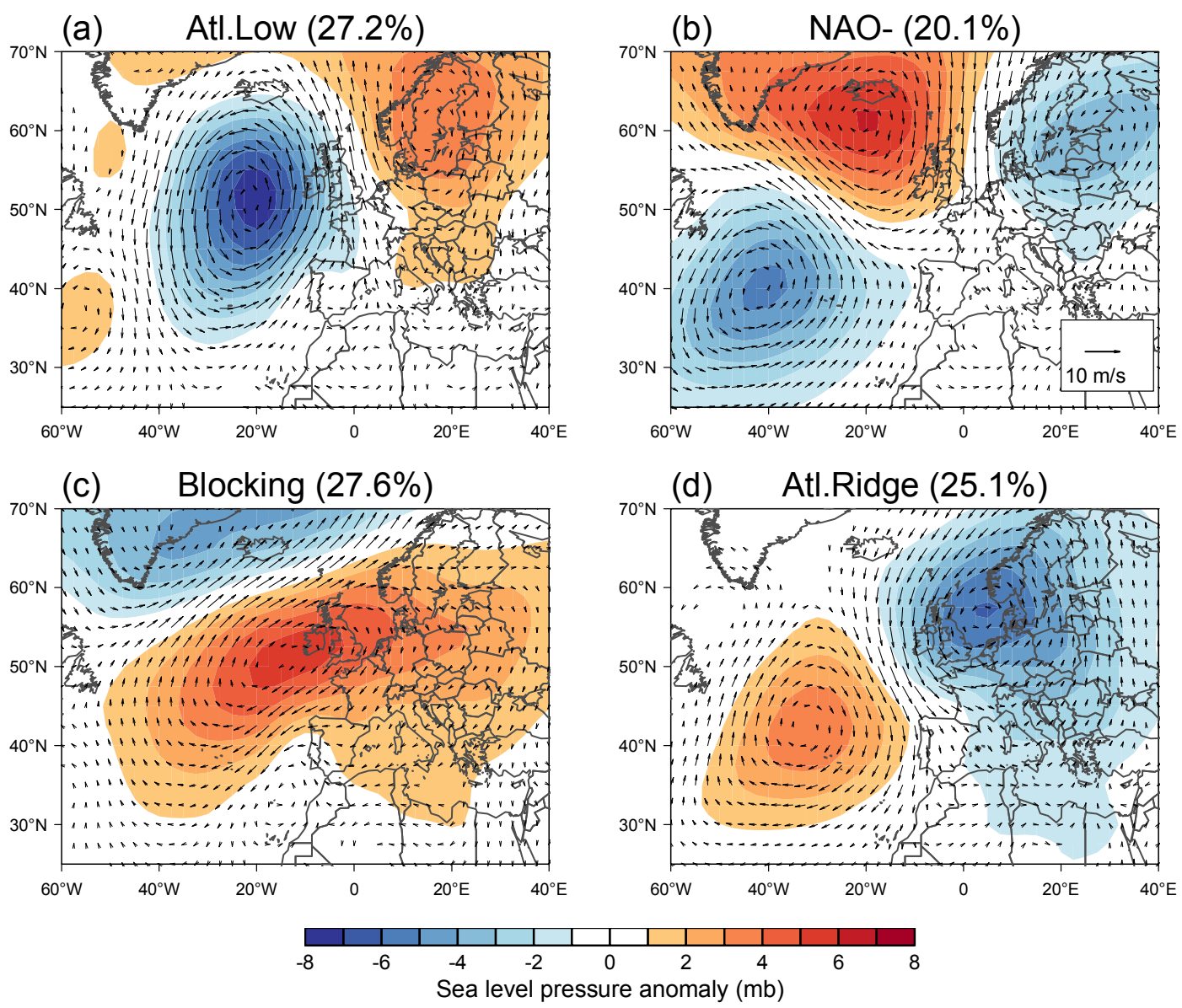
Figure 4: Summer (July and August) averaged sea level pressure (SLP) and winds at $925 \mathrm{hPa}$ (Z_925) composite anomaly for each weather type (WT). Anomalies were computed as the difference between the mean values for each WT and the summer (July and August) 1973-2013 averaged values. Percentages on each subplot indicate the summer mean frequency of WT days over the 1973-2013 period.
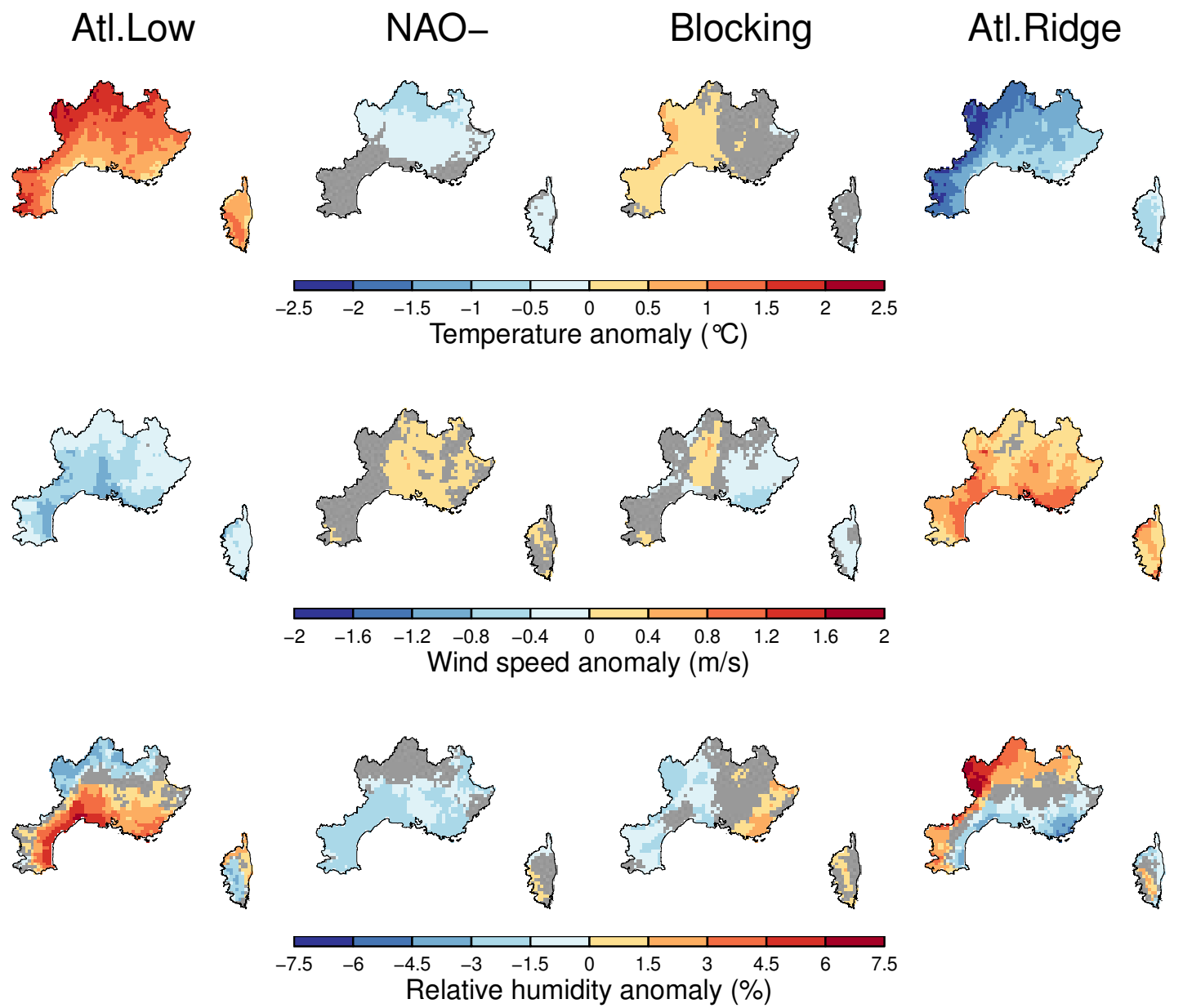
Figure 5: Composites anomalies of daily temperature, wind speed and relative humidity for each Weather type (WT). Composites anomalies for these weather variables were computed as the difference between the daily mean values for each WT and daily summer (July and August) 1973-2013 averages. Anomalous fields were represented only in the areas where the anomaly is statistically significant at the 1\% level (or 99\% confidence level) computed with a two-tailed t-test.
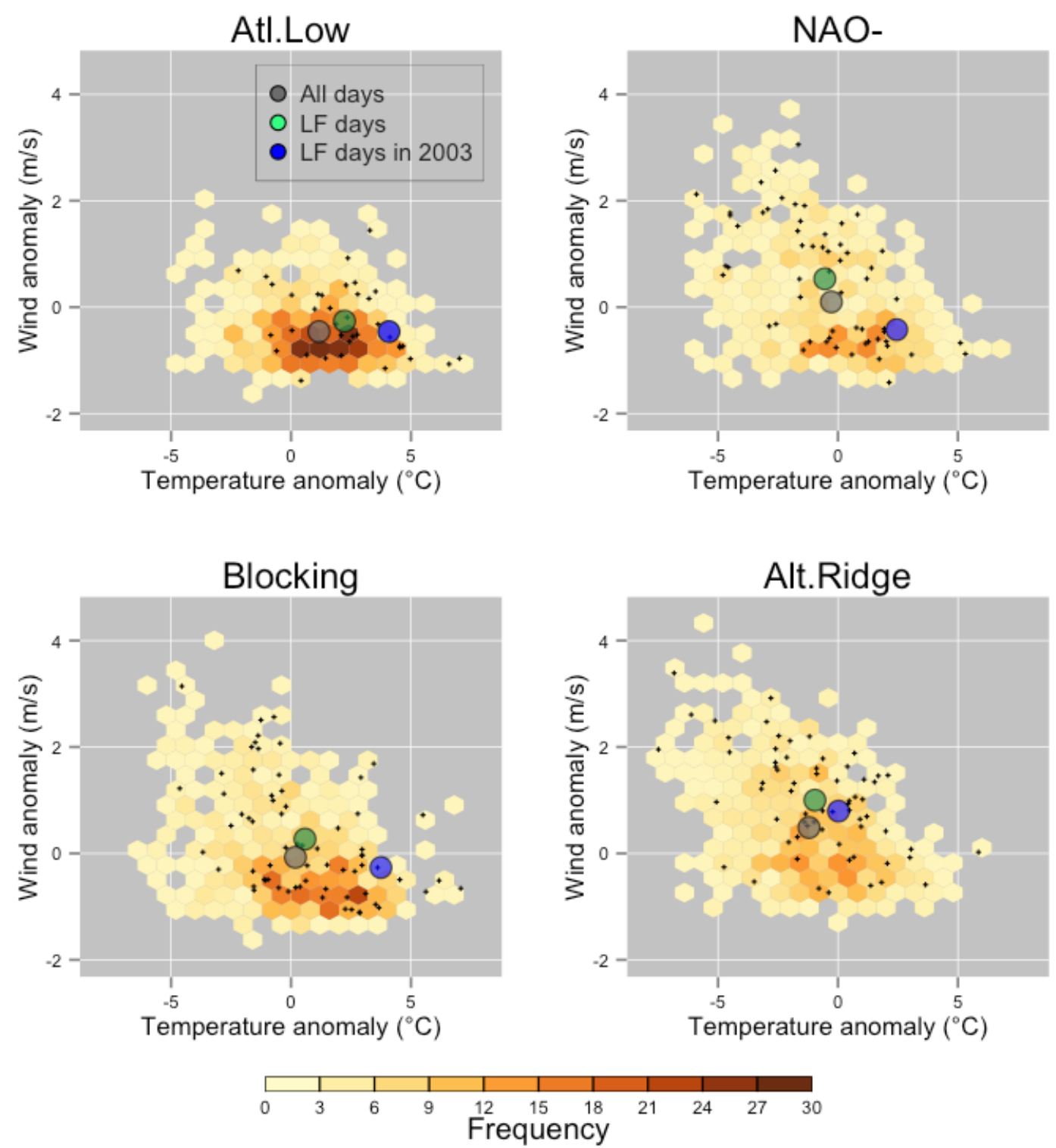


\begin{tabular}{|c|c|c|c|c|c|c|}
\hline & & fire size & Atl.Low & NAO- & Blocking & $\begin{array}{l}\text { Atl.- } \\
\text { Ridge }\end{array}$ \\
\hline \multirow{2}{*}{\multicolumn{2}{|c|}{ Entire region }} & \multirow{2}{*}{$\begin{array}{c}\text { all fires } \\
\text { Large fires }\end{array}$} & \multirow{2}{*}{$\begin{array}{l}0.93 \\
\mathbf{0 , 5 4}\end{array}$} & $1.07 * * *$ & 1.01 & 1.01 \\
\hline & & & & 1,07 & 0,99 & $1,44^{* * *}$ \\
\hline \multirow{2}{*}{\multicolumn{2}{|c|}{ R1 }} & \multirow{2}{*}{$\begin{array}{c}\text { all fires } \\
\text { Large fires }\end{array}$} & \multirow{2}{*}{$\begin{array}{l}0.86 \\
0,46^{* *}\end{array}$} & $1.1 * *$ & $1.15^{* * *}$ & $0.9 * *$ \\
\hline & & & & $1,71^{* * *}$ & 1,19 & 0,81 \\
\hline \multirow{2}{*}{\multicolumn{2}{|c|}{$\mathbf{R} 2$}} & \multirow{2}{*}{$\begin{array}{l}\text { all fires } \\
\text { Large fires }\end{array}$} & \multirow{2}{*}{$\begin{array}{l}1.02 \\
0,77\end{array}$} & 1.05 & $1.13 * * *$ & $0.8 * * *$ \\
\hline & & & & 1,04 & $1,48^{* * *}$ & $0,68^{* *}$ \\
\hline \multirow{2}{*}{\multicolumn{2}{|c|}{ R3 }} & \multirow{2}{*}{$\begin{array}{l}\text { all fires } \\
\text { Large fires }\end{array}$} & \multirow{2}{*}{$\begin{array}{l}0.87^{* * * *} \\
0,51^{* * *}\end{array}$} & $1.06 *$ & $1.04 *$ & $1.05^{*}$ \\
\hline & & & & 0,85 & 1,07 & $1,58^{* * *}$ \\
\hline \multirow{2}{*}{\multicolumn{2}{|c|}{ R4 }} & \multirow{2}{*}{$\begin{array}{c}\text { all fires } \\
\text { Large fires }\end{array}$} & \multirow{2}{*}{$\begin{array}{l}0.87^{* * *} \\
0,71^{*}\end{array}$} & $1.1 * *$ & $0.95 *$ & $1.12 * * *$ \\
\hline & & & & 1,02 & $0,55^{* *}$ & $1,79^{* * *}$ \\
\hline \multirow{2}{*}{\multicolumn{2}{|c|}{ R5 }} & \multirow{2}{*}{$\begin{array}{c}\text { all fires } \\
\text { Large fires }\end{array}$} & $0.95 *$ & $1.08 * *$ & $0.93 * * *$ & $1.07 * *$ \\
\hline & & & $0,44^{* * *}$ & 1,06 & 0,87 & $1,69^{* * *}$ \\
\hline & & & Atl.Low & NAO- & Blocking & Atl.Ridge \\
\hline \multirow{2}{*}{$\begin{array}{l}\text { Entire } \\
\text { region }\end{array}$} & \multicolumn{2}{|c|}{ All fires } & 0.93 & $1.07^{* * *}$ & 1.01 & 1.01 \\
\hline & $L a$ & efires & $\mathbf{0 , 5 4} 4^{* * * *}$ & 1,07 & 0,99 & $1,44^{* * * *}$ \\
\hline \multirow[t]{2}{*}{$\mathbf{R} 1$} & \multirow{2}{*}{\multicolumn{2}{|c|}{$\begin{array}{l}\text { All fires } \\
\text { Large fires }\end{array}$}} & \multirow{2}{*}{$\begin{array}{l}0.86 \\
0,46^{* *}\end{array}$} & $1.1^{* *}$ & $1.15^{* * *}$ & $0.9^{* *}$ \\
\hline & & & & $1,71^{* * *}$ & 1,19 & 0,81 \\
\hline \multirow[t]{2}{*}{$\mathbf{R} 2$} & \multirow{2}{*}{\multicolumn{2}{|c|}{$\begin{array}{l}\text { All fires } \\
\text { Large fires }\end{array}$}} & 1.02 & 1.05 & $1.13^{* * *}$ & $0.8^{* * *}$ \\
\hline & & & 0,77 & 1,04 & $1,48^{* * *}$ & $0,68^{* *}$ \\
\hline $\mathbf{R 3}$ & All & ires & $0.87^{* * *}$ & $1.06^{*}$ & $1.04 *$ & $1.05 *$ \\
\hline & $L a$ & fires & $0,51^{* * *}$ & 0,85 & 1,07 & $1,58^{* * *}$ \\
\hline R4 & All & ìres & $0.87^{* * *}$ & $1.1^{* *}$ & $0.95^{*}$ & $1.12^{* * *}$ \\
\hline & $L a$ & e fires & $0,71^{*}$ & 1,02 & $0,55^{* *}$ & $1,79^{* * *}$ \\
\hline R5 & All & ires & $0.95^{*}$ & $1.08^{* *}$ & $0.93^{* * *}$ & $1.07^{* *}$ \\
\hline & $L a$ & fires & $0,44^{* * *}$ & 1,06 & 0,87 & $1,69^{* * *}$ \\
\hline
\end{tabular}

Table 1: All fires and large fires (> $120 \mathrm{ha}$ ) efficiency of each weather type (WT) for each studied region for the period 1973-2013. In order to evaluate whether the number of LFs is statically different from what we could observe by chance alone, we randomly permuted the days with large fire occurrence on the fire-WT matrix and compared this random LF occurrence to the observed LF occurrence for each WT. This process was repeated 10,000 times and the p-value was computed as the proportion of the observed frequency of LF days higher (or lower) to the random frequency. Significant values are indicated at the $0.1\left(^{*}\right), 0.05\left(^{* *}\right)$ and $0.01\left(\left(^{* * *}\right)\right.$ level. 